\title{
Effect of a Prostaglandin E1 Derivative (OP-1206) and Acetylsalicylic Acid on Electrically Induced Thrombosis in Guinea-Pig Mesenteric Artery and Its Modification by an Inhibitor of Prostaglandin $\mathrm{I}_{2}$ Synthetase, Tranylcypromine
}

\author{
Buichi FUJITANI, Masako WATANABE, Junji KUWASHIMA, \\ Toshimichi TSUBOI, Toshiaki KADOKAWA and *Toshikazu KITAGAWA \\ Research Laboratories, Dainippon Pharmaceutical Co., Ltd., \\ Enoki 33-94, Suita, Osaka 564, Japan \\ *Research Institute, Ono Pharmaceutical Co., Ltd., \\ Sakurai 3-1-1. Shimamoto, Mishima, Osaka 618, Japan
}

Accepted September 13, 1985

\begin{abstract}
The antithrombotic effect of a prostaglandin $E_{1}$ derivative, OP-1206 (17S-20-dimethyl-trans- $\left.\Delta^{2}-\mathrm{PGE}_{1}\right) \cdot \alpha$-cyclodextrin clathrate (OP-1206- $\alpha$-CD), was compared with that of acetylsalicylic acid (ASA) in a electrically induced thrombosis model of guinea-pig mesenteric arteries using intact animals and animals subjected to the superfusion of tranylcypromine (TC, $15 \mathrm{mM}$ ) over their mesentery. The drug-effect was assessed by the change of the threshold voltage for the thrombus formation. 1) TC (1.5-15 mM) lowered the threshold voltage, and the effect was comparable to its inhibitory effect on $\mathrm{PGI}_{2}$ formation in vitro, suggesting that $\mathrm{PGI}_{2}$ generated in mesenteric arteries acts to prevent thrombus formation. 2) In intact animals, OP-1206 $\alpha-C D$ at doses of $0.01-0.3 \mathrm{mg} / \mathrm{kg}$, p.o. (as OP-1206), significantly and dose-dependently elevated the threshold voltage. ASA (30-1000 mg/kg, p.o.) significantly elevated the threshold voltage, but the effect reached to its maximum at $100 \mathrm{mg} / \mathrm{kg}$ and lessened with further increase of ASA. 3) In TC-treated animals, OP-1206- $\alpha$-CD elevated the threshold voltage dose-dependently, but the elevation of threshold voltage by ASA reached to its plateau level which was significantly lower than that obtained with OP-1206 $\alpha-C D$ at $0.3 \mathrm{mg} / \mathrm{kg}$, indicating that the antithrombotic effect of ASA is incomplete in this model. 4) Threshold voltages in TC-treated animals given OP-1206- $\alpha$-CD was significantly lower than those in intact animals at all doses tested, but threshold voltages in TC-treated and intact animals given ASA at 300-1000 mg/kg were not different, suggesting that high doses of ASA inhibits $P G I_{2}$ formation in vivo. Thus, the antithrombotic effect of ASA was restricted by its inhibitory effect on $\mathrm{PGI}_{2}$ formation and its incomplete inhibition on thrombus formation, while such differences were not observed in OP-1206 $\alpha$-CD.
\end{abstract}

Platelets play a important role in the initiation of arterial thrombosis. Therefore, a variety of compounds inhibiting platelet functions were studied with regards to their antithrombotic potential (1). Among these, acetylsalicylic acid (ASA) has been studied for many years, and it has also been used for the treatment of thrombotic diseases such as transient ischemic attack in man (2).
However, the antithrombotic effect of ASA is thought to be restricted by its inhibitory effect on vascular synthesis of prostaglandin $I_{2}\left(P G I_{2}\right)$ (3). $P G I_{2}$ is the most potent endogenous inhibitor of platelet functions (4) and may play an important role in the prevention of thrombus formation (5).

A prostaglandin $E_{1}$ derivative, OP-1206, 17S-20-dimethyl-trans- $\Delta^{2}-\mathrm{PGE}_{1}$, also po- 
tently inhibits platelet functions in vitro (6). Its oral administration also inhibits platelet aggregation and adhesiveness, and it prevents thrombocytopenia induced by the injection of ADP and collagen (7). However, effects of OP-1206 on thrombus formation and $\mathrm{PGl}_{2}$ formation have not been known.

In the present study, we compared the effect of OP-1206 and ASA on electrically induced thrombus formation in guinea-pig mesenteric arteries. The influence of a $\mathrm{PGI}_{2}$ synthetase inhibitor, tranylcypromine (8), was also studied with respect to the antithrombotic effect of these compounds in order to examine their possible effect on $\mathrm{PGI}_{2}$ formation in mesenteric arteries in vivo.

\section{Materials and Methods}

Animals: Male guinea-pigs of the Hartley strain, weighing 360-660 g, were used. A commercial diet (RC-4, Oriental Yeast Co., Japan) and water were given ad libitum.

Experimentally induced thrombosis: Guinea-pigs anesthetised with pentobarbital sodium $(75 \mathrm{mg} / \mathrm{kg}$, s.c.) were subjected to abdominal incision. The jejunum part of the intestinal loops was extended over a plastic plate, and the mesentery was superfused with saline $\left(37^{\circ} \mathrm{C}\right)$. A platinum electrode $(200 \mu \mathrm{m}$ in diameter with shapened tip) as an anode was touched to the mesenteric artery (30$60 \mu \mathrm{m}$ in diameter), and a cathodal electrode was fixed to the edge of the incision. Then, the mesenteric artery was electrically stimulated with a single rectangular pulse (pulse duration of $1000 \mathrm{msec}$ ). The voltage of the stimulation was changed in a stepwise manner at $2.5 \mathrm{~V}$ intervals $(5.0-30 \mathrm{~V})$. The thrombus formation was microscopically observed for $10 \mathrm{~min}$ after each stimulation, and the lowest voltage causing complete occlusion of the vessel by thrombi (threshold voltage for thrombus formation) was determined. Drug-effect was assessed by the change of the threshold voltage.

$\mathrm{PGI}_{2}$ formation in aortic tissue in vitro: The formation of $\mathrm{PGI}_{2}$ in guinea-pig aorta was estimated by a bioassay based on the inhibitory effect of $\mathrm{PGI}_{2}$ on platelet aggregation as previously described (9). Rings of aorta $(10 \mathrm{mg})$ were incubated with $400 \mu$ l of saline buffered with Tris (TBS, $\mathrm{pH}$ 7.6) for $5 \mathrm{~min}$ at $22^{\circ} \mathrm{C}$ under the presence or absence of test compounds. Then, an aliquot of the medium was added to platelet-rich plasma preincubated for $1 \mathrm{~min}$ at $37^{\circ} \mathrm{C}$, and platelet aggregation was induced by ADP $\left(1-2 \times 10^{-6} \mathrm{M}\right)$. The amount of released $\mathrm{PGI}_{2}$ was calculated by comparison of its antiaggregatory potency with that of a known amount of synthetic $\mathrm{PGI}_{2}$ sodium salt.

Test compounds: OP- $1206 \cdot \alpha$-cyclodextrin clathrate (OP-1206. $\alpha$-CD) containing $2.93 \%$ of its active principle, OP-1206, was used throughout the experiments, and doses and concentrations of OP-1206- $\alpha$-CD were expressed as those of OP-1206. OP-1206. $\alpha$ $\mathrm{CD}$ was chemically more stable than OP1206, but its inhibitory effect on platelet functions in vitro and ex vivo was equipotent to that of OP-1206 (Data are not shown). OP-1206. $\alpha-C D$ dissolved in saline was orally given $4 \mathrm{hr}$ before the electrical stimulation. ASA suspended in $0.5 \%$ tragacanth solution was orally given $3 \mathrm{hr}$ before the stimulation. Tranylcypromine dissolved in saline was directly superfused over the mesentery from $10 \mathrm{~min}$ before the stimulation. In in vitro experiments, these compounds were dissolved in TBS.

Chemicals: OP-1206. $\alpha-C D$ and $\mathrm{PGI}_{2}$ sodium salt were synthesized by Ono Pharmaceutical Co., Ltd., Japan. ASA was obtained from Aldrich Chem. Co., U.S.A., and tranylcypromine was from Sigma Chem. Co., U.S.A.

Statistical analysis: Data are shown as the mean \pm S.E. and analysed with Student's $t$-test.

\section{Results}

Effects of tranylcypromine on aortic $\mathrm{PGI}_{2}$ formation in vitro and thrombus formation in mesenteric arteries: Tranylcypromine (TC) at $0.75-7.5 \mathrm{mM}$ inhibited the aortic $\mathrm{PGI}_{2}$ formation in vitro in a concentrationdependent manner (Fig. 1A). TC (1.5-15 $\mathrm{mM}$ ) superfused over the mesentery also lowered the threshold voltage for the thrombus formation (Fig. 1B). The concentrations of $T C$ inhibiting $P G I_{2}$ formation and lowering the threshold voltage were comparable. 
(A)

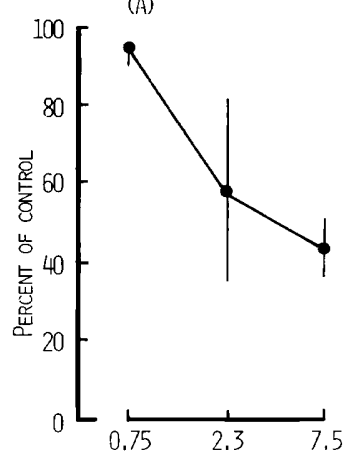

CONCENTRATION OF TRANYLCYPROMINE (mM)

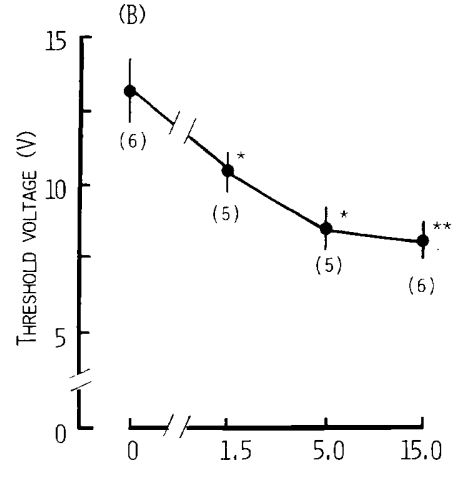

CONCENTRATION OF TRANYLCYPROMINE (mM)

Fig. 1. Effect of tranylcypromine on in vitro $\mathrm{PGl}_{2}$ formation and thrombus formation in guinea-pigs. A: Inhibition of $\mathrm{PGl}_{2}$ formation in guinea-pig aorta in vitro. Each dot is the mean $\pm \mathrm{S}$.E. of three experiments. In the contro!, aortic tissue released $9.7 \pm 0.88 \mathrm{ng} / 10 \mathrm{mg}$ tissue $/ 5 \mathrm{~min}$ of $\mathrm{PGI}_{2}$. B: Enhancement of thrombus formation in electrically induced thrombosis model in guinea-pig mesenteric artery. Each dot is the mean \pm S.E. Parentheses indicate the numbers of animals used. " ${ }^{* *}$ : Differences from the control are statistically significant with $P<0.05$ and $P<0.01$, respectively. Tranylcypromine was superfused over the mesentery from $10 \mathrm{~min}$ before the electrical stimulation.

\section{Antithrombotic effect of OP-1206. $\alpha-C D$} and ASA: The antithrombotic effect was examined both in intact guinea-pigs and guinea-pigs subjected to superfusion of TC at $15 \mathrm{mM}$ over their mesentery.

OP-1206. $\alpha-C D \quad(0.01-0.3 \mathrm{mg} / \mathrm{kg}$, p.o.) significantly elevated threshold voltages in intact and TC-treated animals in a dosedependent manner (Fig. 2). The threshold voltages in TC-treated animals given OP$1206 \cdot \alpha-C D$ were significantly and consistently lower than those in intact animals given OP-1206. $\alpha-C D$ at all doses tested.

ASA (30-1000 mg/kg, p.o.) also elevated threshold voltages in intact and TC-treated animals significantly, although its effect was $1 / 3000$ times less potent than that of OP$1206 \cdot \alpha-C D$ (Fig. 3).

However, the antithrombotic property of ASA was somewhat different from that of OP-1206- $\alpha$-CD. In intact animals, the elevation of threshold voltage by ASA reached to its maximum of $21 \mathrm{~V}$ at $100 \mathrm{mg} / \mathrm{kg}$, and a further increase of ASA caused the reduction of its antithrombotic effect (Fig. 3). In TC-treated animals, the elevation of threshold voltages reached to its plateau of $17 \mathrm{~V}$ at $100-1000 \mathrm{mg} / \mathrm{kg}$. The threshold voltage of this plateau level was signifi-

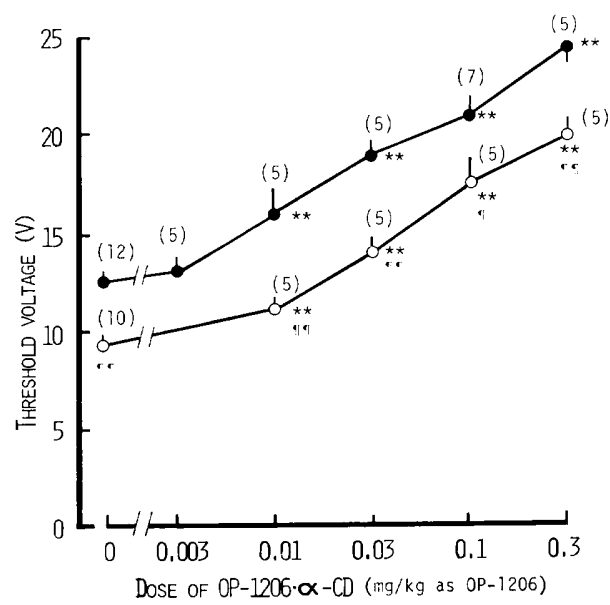

Fig. 2. Antithrombotic effect of OP-1206. $\alpha-C D$ in electrically induced thrombosis model in intact and tranylcypromine-treated (O) guinea-pigs. Each dot is the mean \pm S.E. Parentheses indicate the numbers of animals used. ${ }^{*},{ }^{* *}$ : Differences from the intact or tranylcypromine-treated controls are statistically significant with $\mathrm{P}<0.05$ and $\mathrm{P}<0.01$. respectively. $\mathbf{I}$. $\mathbf{I}$ : Differences between intact and tranylcypromine-treated animals are statistically significant with $P<0.05$ and $P<0.01$, respectively. OP-1206. $\alpha-C D$ was orally given $4 \mathrm{hr}$ before the electrical stimulation, and tranylcypromine $(15 \mathrm{mM})$ was superfused from $10 \mathrm{~min}$ before the stimulation. 
cantly lower than that obtained with OP$1206 \cdot \alpha-C D$ at $0.3 \mathrm{mg} / \mathrm{kg}$ in TC-treated animals. The threshold voltages of $\mathrm{TC}$ treated animals given ASA at $10-100 \mathrm{mg} / \mathrm{kg}$ were significantly lower than those in intact animals given the same doses of ASA, but threshold voltages of intact and TC-treated animals given ASA at $300-1000 \mathrm{mg} / \mathrm{kg}$ were not different (Fig. 3).

In vitro effect of OP-1206 $\alpha-C D$ and ASA on $\mathrm{PGI}_{2}$ formation in aorta: ASA at $300 \mu \mathrm{g} / \mathrm{ml}$ inhibited $\mathrm{PGI}_{2}$ formation in guinea-pig aortic tissue, but OP-1206. $\alpha-C D$ at $0.5-1.0 \mathrm{ng} / \mathrm{ml}$ did not (Table 1).

\section{Discussion}

The superfusion of TC over the mesentery enhanced the thrombus formation at concen-

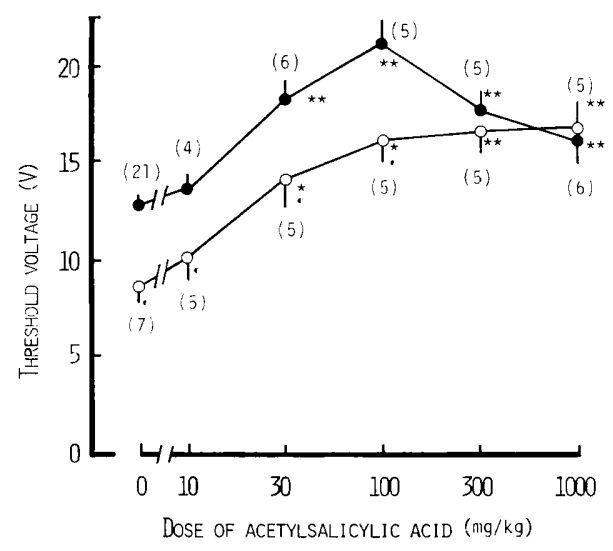

Fig. 3. Antithrombotic effect of acetylsalicylic acid in electrically induced thrombosis model in intact (O) and tranylcypromine-treated (O) guinea-pigs. Acetylsalicylic acid was orally given $3 \mathrm{hr}$ before the electrical stimulation. Other legends to the figure are the same as described in Fig. 2. trations inhibiting $\mathrm{PGI}_{2}$ formation in vitro. suggesting that endogenously formed $\mathrm{PGI}_{2}$ in mesenteric arteries acts to prevent thrombus formation in this model. A similar result has been reported by Bourgain (5). Thus, testing the antithrombotic effect of a certain compound in TC-treated animals may enable us to exclude the indirect effect of the compound through its effect on $\mathrm{PGI}_{2}$ formation, and the difference of threshold voltages between intact and TC-treated animals given a certain compound may reflect its effect on $\mathrm{PGI}_{2}$ formation in vivo.

OP-1206. $\alpha$-CD and ASA inhibited thrombus formation by oral administration. and the effect of OP-1206- $\alpha$-CD was more potent than that of ASA. Antithrombotic doses of both compounds are comparable to their inhibitory doses on platelet functions in guinea-pigs reported by us (7, 10). indicating that the antithrombotic effect of these compounds originated from their inhibitory activities on platelet function. However, the dose-effect relationships of these two compounds were somewhat different.

Firstlv, in TC-treated animals, the antithrombotic effect of OP-1206 $\alpha-C D$ increased in a dose-dependent manner, whereas that of ASA reached to its plateau level which was significantly lower than the threshold voltage obtained with OP-1206. $\alpha-C D$ at $0.3 \mathrm{mg} / \mathrm{kg}$. The difference may come from the different inhibitory mechanism of OP$1206 \cdot \alpha-C D$ and ASA on platelet functions. A compound that increases platelet cyclic AMP like OP-1206 (6) inhibits all of the activation process of platelets (11), but ASA only inhibits an activation process related to arachidonate-thromboxane pathway (12).

Table 1. In vitro effect of OP-1206- $\alpha-C D$ and acetylsalicylic acid on $\mathrm{PGI}_{2}$ formation in guinea-pig aorta

\begin{tabular}{|c|c|c|c|}
\hline Treatment & Concentration & & $\begin{array}{l}\mathrm{PGI}_{2} \text { formation } \\
(\mathrm{ng} / 10 \mathrm{mg} \text { tissue } / 5 \mathrm{~min})\end{array}$ \\
\hline Control & & $(12)$ & $7.60 \pm 0.76$ \\
\hline $\mathrm{OP}-1206 \cdot \alpha-\mathrm{CD}$ & $\begin{array}{l}0.5 \mathrm{ng} / \mathrm{ml} \text { as } \mathrm{OP}-1206 \\
1.0\end{array}$ & $\begin{array}{l}(3) \\
(3)\end{array}$ & $\begin{array}{l}8.64 \pm 0.33 \\
8.61 \pm 1.66\end{array}$ \\
\hline Acetylsalicylic acid & $\begin{array}{l}100 \mu \mathrm{g} / \mathrm{m} ! \\
300\end{array}$ & $\begin{array}{l}(3) \\
(3)\end{array}$ & $\begin{array}{l}6.40 \pm 1.21 \\
3.80 \pm 0.23^{* *}\end{array}$ \\
\hline
\end{tabular}

The values in the table are the means \pm S.E. Parentheses indicate the numbers of experiments. ${ }^{* *}$ : A difference from the control is statistically significant with $P<0.01$. 
Secondly, the consistent differences between threshold voltages in intact and TC-treated animals given OP-1206- $\alpha-C D$ indicate that the compound has little effect on $\mathrm{PGI}_{2}$ formation. On the contrary, threshold voltages in intact and TC-treated animals given ASA at $300-1000 \mathrm{mg} / \mathrm{kg}$ were not different. Thus, ASA at high doses may inhibit $\mathrm{PGI}_{2}$ formation as well as thrombus formation, and this inhibition of $\mathrm{PGI}_{2}$ formation may explain a part of the lessened antithrombotic effect of ASA at these doses in intact animals. A similar lessened antithrombotic effect or prothrombotic effect of ASA has been reported earlier $(3,13)$.

The above results are coincident with the result of in vitro experiments on $\mathrm{PGI}_{2}$ formation in aortic tissue. OP-1206. $\alpha$-CD $(0.5-1.0 \mathrm{ng} / \mathrm{ml})$ did not inhibit $\mathrm{PGI}_{2}$ formation, although these concentrations of OP-1206 markedly inhibited guinea-pig platelet functions (6). ASA inhibited $\mathrm{PGI}_{2}$ formation at $300 \mu \mathrm{g} / \mathrm{ml}$. This concentration is 30-100 times higher than the concentrations of ASA inhibiting platelet adhesiveness (10), and the ratio is roughly comparable to the ratio of the prothrombotic dose/antithrombotic dose of ASA (ratio: 10-30). The discrepancy may come from the difference of the vascular tissue used, i.e., aorta and mesenteric artery.

In summary, ASA inhibited thrombus formation, but its antithrombotic effect was lessened at its high doses. The reduction of the antithrombotic effect may result from its inhibitory effect on $\mathrm{PGI}_{2}$ formation and its incomplete inhibition of the activation process of platelets. In contrast to ASA, OP$1206 \cdot \alpha-C D$ inhibited thrombus formation in a dose-dependent manner. This property of OP-1206 $\alpha-C D$ together with its vasodilating effect (7) may be favorable for the treatment of ischemic vascular diseases.

\section{References}

1 Blakely, J.A.: Platelet suppressing drugs in arterial disease (Review). Thromb. Haemost. 39, 294-303 (1978)

2 Canadian Cooperative Stroke Study Group: Randamized trial of aspirin and sulfinpyrazone in threatened stroke. N. Engl. J. Med. 299, 53-59 (1978)
3 Kelton, J.G., Hirsh, J., Carter, C.J. and Bucchanan, M.R.: Thrombogenic effect of highdose aspirin in rabbits. Relationship to inhibition of vessei wall synthesis of prostaglandin $\mathrm{I}_{2}$-like activity. J. Clin. Invest. 62, 892-895 (1978)

4 Moncada, S., Higgs, E.A. and Vane, J.R.: Human arterial and venous tissue generate prostacyclin (prostaglandin X), a potent inhibitor of platelet aggregation. Lancet 1, 18-20 (1976)

5 Bourgain, R.H.: Inhibition of $\mathrm{PGI}_{2}$ (prostacyclin) synthesis in the arterial wall enhances the formation of white platelet thrombi "in vivo". Haemostasis 7, 252-255 (1978)

6 Tsuboi, T., Fujitani, B., Maeda, J., Yoshida, K., Shimizu, M., Kawasaki, A., Okegawa, T. and Tsuboshima, M.: Effect of OP-1206, a prostaglandin $E_{1}$ derivative, on guinea-pig platelet functions. Thromb. Res. 20, 573-580 (1980)

7 Tsuboi, T., Hatano, N., Nakatsuji, K., Fujitani, B., Yoshida, K., Shimizu, M., Kawasaki, A., Sakata, M. and Tsuboshima, M.: Pharmacological evaluation of OP-1206, a prostaglandin $E_{1}$ derivative, as an antianginal agent. Arch. Int. Pharmacodyn. Ther. 247, 89-102 (1980)

8 Gryglewski, R.J., Bunting, S., Moncada, S., Flower, R.J. and Vane, J.R.: Arterial walls are protected against deposition of platelet thrombi by a substance (prostaglandin $X$ ) which they makes from prostaglandin endoperoxides. Prostaglandins 12, 685-713 (1976)

9 Fujitani, B., Maeda, J., Tsuboi, T., Kadokawa, T. and Shimizu, M.: Effect of gliclazide on prostaglandin $\mathrm{I}_{2}$ formation in normal and streptozotocin-induced diabetic animals. Japan. J. Pharmacol. 33, 965-970 (1983)

10 Fujitani, B., Tsuboi, T., Takeno, K., Yoshida, K. and Shimizu, M.: Inhibition of human and animal platelet adhesiveness to glass bead columns by adenosine, dipyridamole, chlorpromazine and acetylsalicylic acid. Thromb. Haemost. 36, 401-410 (1976)

11 Feinstein, G.A., Rodan, G.A. and Culter, L.S.: Cyclic AMP and calcium in platelet functions. In Platelets in Biology and Pathology, Edited by Gordon, J. L., Vol. 2, p. 437-472, Elsevier/ North Holland Biomedical Press, Amsterdam (1981)

12 Mclntire, B.A. and Richard, B.P.: Effect of three nonsteroidal antiinflammatory agents on platelet functions and prostaglandin synthesis in vitro. Thromb. Res. 12, 67-77 (1977)

13 Zimmerman, R., Thissen, M., Mörl, H. and Weckesser, G.: The paradoxical thrombogenic effect of aspirin in experimental thrombosis. Thromb. Res. 16, 843-846 (1979) 